\title{
Commentary: Patients older than age 65 years: Young or old for a ventricular assist device program? Is it time to restrict the indication for them?
}

\author{
Francesco Formica, MD
}

\footnotetext{
From the Mechanical Circulatory Support Program, Cardiac Surgery Unit, San Gerardo Hospital, Monza, Italy, and Department of Medicine and Surgery, University of Milano-Bicocca, Milan, Italy. Disclosures: Author has nothing to disclose with regard to commercial support.

Received for publication Nov 6, 2018; accepted for publication Nov 7, 2018; available ahead of print Dec 6, 2018. Address for reprints: Francesco Formica, MD, Clinica Cardiochirurgica Ospedale San Gerardo, ASST Monza, Via G.B. Pergolesi 33, 20052, Monza, Italy (E-mail: francesco_formica@fastwebnet.it).

J Thorac Cardiovasc Surg 2019;158:476-7

$0022-5223 / \$ 36.00$

Copyright (C) 2018 by The American Association for Thoracic Surgery

https://doi.org/10.1016/j.jtcvs.2018.11.016
}

Congestive heart failure is a common pathology that increases with age. Medical treatment of patients with congestive heart failure offers limited survival and poor chance of functional recovery. Ventricular assist devices (VADs), mostly the last generation, may offer significant benefits in patients with refractory heart failure. Nevertheless, although heart transplantation (HT) has an acceptable long-term survival and represents the gold standard treatment for such patients, the number of HT procedures has not increased during the past decade. This is mostly due to the widespread belief of not exceeding the 65-years age threshold and the low pool of donors. Therefore, it appears that VAD therapy is becoming the standard approach for patients with refractory heart failure who are ineligible for HT. VAD implant presents a number of challenging decisions as well as technical challenges. Neurologic, renal, nutritional, and psychosocial assessments are of paramount importance before considering patients eligible for VAD implant. Can we include patients older than age 65 to 70 years in VAD therapy? If yes, can we extend the indication for VAD therapy to frail older patients? What criteria should patients meet to be defined as frail, because no standard definition for frailty exists? Lindvall and colleagues ${ }^{1}$ report worthy results about the in-hospital mortality of a very large cohort of patients included in the National Inpatient Sample and who underwent VAD implant between 2010 and 2014. The authors stratified patients according the age; patients older than age 65 years were defined as older. More than 15,000 VAD implants were identified and among them more than 4000 were implanted in patients older than age 65 years. Compared with patients younger than age 65 years, older patients have a greater incidence of in-hospital mortality (29.4\% vs $48.2 \%$, respectively) associated with preoperative interventions, including extracorporeal membrane oxygenation support, prolonged ventilation, cardiac surgery, and hemodialysis. Furthermore, among patients older than age 65 years, the rate of HT dramatically decreases. It is likely that patients older than age 65 years represent those

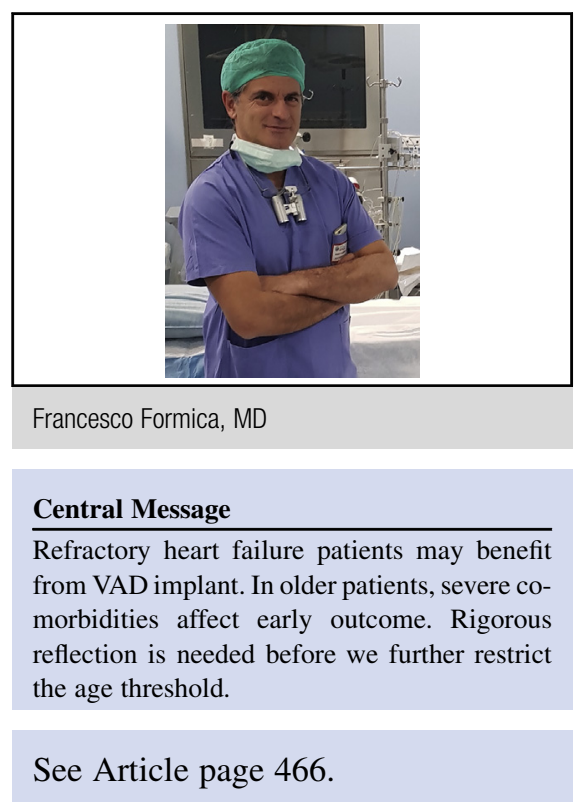

with a greater index of frailty, ${ }^{2}$ which may affect the indication for both VAD implant and HT. One more important message coming from the study by Lindvall and colleagues ${ }^{1}$ is that among patients younger than age 65 years the number of VAD implants increases while the incidence of in-hospital mortality decreases, maybe because of evolving technologies and increased VAD team experience, although these factors were not analyzed in the study. Instead, in older patients, despite the increasing number of VAD implants, the in-hospital mortality does not reduce.

On the 1 hand, conflicting data about the early and midterm outcome for older patients undergoing VAD implant have been reported. ${ }^{3-6}$ On the other hand, older patients with a high grade of frailty, ${ }^{2,7}$ or assisted by extracorporeal membrane oxygenation before implant, ${ }^{8}$ or with advanced renal failure or hemodialysis ${ }^{6,9}$ experienced poor prognosis. Although the database of this study, as acknowledge by the authors, ${ }^{1}$ is more of administrative than clinical nature and clinical and surgical data are not complete, a question arises: Should we further restrict the indication for VAD implant in patients older than age 65 years?

\section{References}

1. Lindvall C, Udelsman B, Malhortra D, Brovman EY, Urman RD, D'Alessandro DA, et al. In-hospital mortality in older patients after ventricular assist device implantation: a national cohort study. J Thorac Cardiovasc Surg. 2019;158: 466-75.e4. 
2. Dunlay SM, Park SJ, Joyce LD, Daly RC, Stulak JM, McNallan SM, et al. Frailty and outcomes after implantation of left ventricular assist device as destination therapy. J Heart Lung Transpl. 2014;33:359-65.

3. Adamson RM, Stahovic M, Chillcott S, Baradarian S, Chammas J, Jaski B, et al. Clinical strategies and outcomes in advanced heart failure patients older than 70 years of age receiving the HeartMate II left ventricular assist device. J Am Coll Cardiol. 2011;57:2487-95.

4. Allen JG, Kilic A, Weiss ES, Arnaoutakis GJ, George TJ, Shah A, et al. Should patients 60 years and older undergo bridge to transplantation with continuous-flow left ventricular assist device? Ann Thorac Surg. 2012;94: 2017-24.

5. Kim JH, Singh R, Pagani FD, Desai SS, Hauglund NA, Dunlay SM, et al. Ventricular assist device therapy in older patients with heart failure: characteristics and outcomes. J Card Fail. 2016;22:981-7.
6. Muslem R, Caliskan K, Akin S, Yasa YE, Sharma K, Gilotra NA, et al. Effect of age and renal function on survival after left ventricular assist device implantation. Am J Cardiol. 2017;120:2221-5.

7. Tse G, Gong M, Wong SH, Wu WKK, Bazoukis G, Lampropoulos K, et al Frailty and clinical outcomes in advanced heart failure patients undergoing left ventricular assist device implantation: a systematic review and meta-analysis. J Am Med Dir Assoc. 2018;19:255-61.

8. Han JJ, Chung J, Chen CW, Gaffey AC, Sotolongo AC, Justice C, et al. Differen clinical course and complications in interagency registry for mechanically assisted circulatory support 1 patients managed with or without extracorporeal membrane oxygenation. ASAIO J. 2018;64:318-22.

9. Bansal N, Hailpern SM, Katz R, Hall YN, Tamura MK, Kreuter W, et al. Outcomes associated with left ventricular assist devices among recipients with and without end-stage renal disease. JAMA Intern Med. 2018;178:204-9. 